\title{
Impact of comprehensive smoke-free policy compliance on SHS exposure and health condition of the Georgian population
}

\author{
George Bakhturidze', Nana Peikrishvili', Kakha Gvinianidze²
}

\begin{abstract}
INTRODUCTION Georgia made steps forward in 2017 and adopted new amendments to its tobacco control legislation, which mostly correspond to the FCTC requirements. Among other changes in the regulations is a ban on smoking in public buildings and public transport, with a few exemptions (casinos, big slot clubs, performances in theatres, taxis). The regulation entered into force on 1 May 2018.

METHODS The aim of the study is to assess the outcomes of the comprehensive smoke-free legislation in Georgia. We used a logical model for data collection and analysis. Our evaluation focuses on smoking prevalence related survey data, SHS exposure, monitoring results on compliance of new tobacco control regulations, Quitline data, and air quality measurement results.

RESULTS The indoor air quality improved by $91 \%$ in the hospitality sector (from 1408 to $126 \mu \mathrm{g} / \mathrm{m}^{3}$ in 2018 and $117 \mu \mathrm{g} / \mathrm{m}^{3}$ in 2019 ), by $80 \%$ in public settings (from 531 to $112 \mu \mathrm{g} / \mathrm{m}^{3}$ in 2018 and $98 \mu \mathrm{g} / \mathrm{m}^{3}$ in 2019) and sufficiently in healthcare facilities (from 219 to $97-98 \mu \mathrm{g} / \mathrm{m}^{3}$ in $2018-2019$ ). Demand for Quitline services increased by $30 \%$. New cases of AMI declined by $32 \%$ during 2017-2019.

CONCLUSIONS A comprehensive smoke-free policy with a high level of compliance $(\geq 95 \%)$ had a positive impact on the decline of SHS exposure and tremendous improvement of indoor air quality in public places and promotes a decrease in illnesses related to the cardiovascular system in Georgia. Also, demand increased for smoking-cessation services.
\end{abstract}

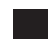

\section{AFFILIATION}

1 Framework Convention on Tobacco Control Implementation and Monitoring Center, Tbilisi, Georgia

2 World Health Organization

Country Office, Tbilisi, Georgia

CORRESPONDENCE TO

George Bakhturidze. Framework Convention on Tobacco Control Implementation and Monitoring Center, Tbilisi, Georgia. E-mail: iayd@yahoo.com ORCID ID: https://orcid.org/0000-0002-55785189

\section{KEYWORDS}

tobacco control, SHS exposure, smoke-free policy, health impact

Received: 1 February 2021

Revised: 25 October 2021

Accepted: 27 October 2021

\section{INTRODUCTION}

The World Health Organization (WHO) noted in 2019 that tobacco kills more than 8 million people each year. More than 7 million of those deaths are associated with users and ex users of tobacco products, while more than 1.2 million deaths are the result of non-smokers being exposed to secondhand smoke $^{1}$. After several decades of research, it is now clear that there is a multitude of health risks posed by active and passive (secondhand) smoking on different organs and systems of the human body. The $\mathrm{WHO}^{1}$ and the US Center for Disease Control and Prevention
$(\mathrm{CDC})^{2}$ have provided extensive overviews of the health risks of smoking, underlining that smoking and other forms of tobacco use can damage nearly every part of the body. Due to nicotine, smoking can lead to addiction and dependence, with nicotine reported as an addictive drug on par with heroin ${ }^{3}$.

Exposure to secondhand smoke (SHS) among adults is also linked with increased risks of several diseases such as: cardiovascular diseases (atherosclerosis, heart attack, stroke); diseases of the respiratory systems (asthma, chronic respiratory symptoms, decreased pulmonary function, chronic 
obstructive pulmonary diseases); different types of cancers (lung cancer, nasal sinus cancer, larynx cancer, breast cancer, etc. $)^{4,5}$.

Reviews of the literature demonstrate that a smoke-free policy improves the health condition of the population ${ }^{6}$. A review of the literature published between 2000 and 2010 on health outcomes following introduction of comprehensive a smokefree policy indicated that smoke-free regulations lead to improved indoor air quality, reduced exacerbations of asthma, fewer acute myocardial infarctions (AMIs) and an overall improvement in the health of hospitality workers and general public ${ }^{7}$. Goodman et al. ${ }^{8}$ reviewed studies published between 2004 and 2009 and concluded that significant and consistent evidence from around the world shows that comprehensive smoke-free laws are associated with improved respiratory health and reduced cardiovascular disease (CVD). An additional review of 77 studies from 21 countries concluded that 'the evidence supports a temporal association between the introduction of national smoke-free bans and subsequent reductions in smoking-related morbidity and mortality', and that the 'evidence for smoking bans in improving cardiovascular, respiratory and perinatal health outcomes for both smokers and nonsmokers are persuasive ${ }^{9}$.

According to the STEP wise approach to noncommunicable disease risk factor surveillance (STEPS) performed in Georgia in $2016^{10}$, around $31 \%$ of adults smoked tobacco $(57 \%$ of men and $7 \%$ of women self-reported smoking, while $12.2 \%$ of women had a positive urine cotinine test). Furthermore, tobacco smoking among adolescents aged $13-15$ years was $12.6 \%$ ( $16.9 \%$ boys, $7.6 \%$ girls) and among adolescents aged 16 years $18 \%(26 \%$ boys, $9 \%$ girls) in 2015 and $2017^{11,12}$. Tobacco use in Georgia causes 11400 deaths annually, among them at least 2100 among non-smokers ${ }^{13}$. Secondhand smoke at home affects $43 \%$ of the population and $15.8 \%$ of employees are exposed to secondhand smoke at their workplace ${ }^{10}$. The Global Burden of Disease - Country Profile overview showed that Romania and Georgia had the third highest position by tobacco related mortality in Europe ${ }^{14}$.

The total economic cost of smoking (from health expenditures and productivity losses together) equaled to a purchasing power parity of US\$1852 billion in 2012 , equivalent in magnitude to $1.8 \%$ of the world's annual gross domestic product (GDP). Almost $40 \%$ of this cost occurred in developing countries, highlighting the substantial burden these countries suffer ${ }^{15}$. The direct costs to society of smoking far outweigh any benefits that might be accruable at least when considered from the perspective of socially desirable outcomes ${ }^{16}$. The investment case for FCTC implementation in Georgia prepared by UNDP/WHO in 2018 found that Georgia is losing about 825 million GEL ( 100 Georgian Lari about US\$32) equivalent to $2.43 \%$ of its annual GDP due to tobacco use. Of this loss, 327 million is direct costs of tobacco use, such as healthcare costs and the remaining part represents indirect costs related to loss of productivity and premature mortality ${ }^{10}$.

To address these problems, Georgia made a step forward in 2017 and adopted new amendments to tobacco control legislation, which mostly corresponded to the FCTC requirements. Among other changes in the regulations is a ban on smoking in public buildings and public transport with a few exemptions (casinos, big slot clubs, performances in theatres, taxis). The regulation entered into force on 1 May $2018^{17}$. The compliance level of new regulations is very high around $96 \%^{18}$, from which we can assume that Georgian new smoke-free policy may have some positive impact on SHS exposure and health condition of the Georgian population.

It was opportunity for us to collect appropriate data before and after the comprehensive smoke-free policy and observe proper changes regarding health impacts. The aim of this study is to assess the health outcomes of comprehensive smoke-free legislation in Georgia. We used logical model for data collection and analysis. Our evaluation focuses on smoking prevalence related survey data, SHS exposure, monitoring results on compliance of new tobacco control regulations, Quitline data and air quality measurement results.

\section{METHODS}

We collected data from different sources before (baseline: 2016-2017) and after one year and half (2018-2019) of entering into force the new tobacco control regulations. Statistical health data were taken from the Healthcare Statistical Yearbooks 
(2016-2019), of the Ministry of Internally Displaced Persons from the Occupied Territories, Labor, Health and Social Affairs of Georgia (Ministry of Health - MoF). Diseases are presented through the International Classification of Diseases (ICD-10). We used incidence data regarding new cases for acute myocardial infarction (AMI), because no other data were provided in the statistics regarding AMI.

New regulations compliance data and air quality data were taken from the FCTC Implementation and Monitoring Center in Georgia. The Center monitors around 10000 different organizations throughout the country regarding compliance to the smoke-free policy. Monitors use special software Magpi+ or Google forms. All results of observational monitoring, together with photos or videos regarding violations, are accumulated in the database. The Center provided generalized data regarding monitoring results from May 2018 to the end of 2019. We received information from the Ministry of Interior Affairs of Georgia on violations of smokefree regulations.

For the measuring indoor air quality in the buildings where smoking is regulated, the Center uses air particles personal monitor SidePakTM, Model AM510, which measures particles $<2.5 \mu \mathrm{m}$ which mostly relates to cigarette smoke exposure. A minimum of 150 facilities were observed per year in different cities of Georgia during May-Dec, 2017-2019. Duration of air quality measurement is about $30 \mathrm{~min}$ on average. The time for observation was selected according to the type of the facility. For instance, we observed the hospitality sector at evening time, while public buildings were observed during the daytime period. The Center provided data before and after adoption of the new effective regulations.

We collected Quitline data from the National Center for Diseases Control (NCDC), which manages services regarding the issue. We collected data only after new regulations entered into force, because no statistics were collected before 1 May 2018. The representatives informed us that before May 2018 there was only a few calls on the Quitline and it made no sense to register the calls and make registry.

\section{RESULTS}

\section{Compliance with the law}

The FCTC Implementation and Monitoring Center in Georgia conducts monitoring of the enforcement of new regulations in the country since 1 May 2018 within the framework of the state program on Health Promotion. We analyzed data for the period 1 May to 31 December for both 2018 and 2019. Table 1 gives the enforcement level (\%) of the smoke-free law in different facilities.

On average, the level of compliance was around $95 \%$ in 2018 and $96 \%$ in 2019 . Highest level of compliance was in the hospitality sector (average $98 \%$ ) and lowest in public buildings (average $91 \%)$. Information provided by the Ministry of Internal Affairs shows that the number of smoking prohibition violations in the period 1 May to 31 December was 269 in 2018 and 192 in 2019, i.e. there were $29 \%$ less violations in 2019 compared to 2018 .

\section{Indoor air quality and exposure of population to secondhand smoke (SHS)}

After the new regulations entered into force, indoor air pollution by tobacco smoke in public places and accordingly secondhand smoke exposure had decreased. Before adoption of new regulations (in 2016), the secondhand smoke exposure in adolescents at enclosed public places was $58.6 \%^{8}$. Secondhand smoke prevalence among adults at working places was $15.8 \%$ in $2016^{6}$.

According to the data from the FCTC Implementation and Monitoring Center in Georgia (unpublished data, 2020)*, air quality in different facilities was alarming poor before the law entered into force in 2017-2018. For instance, the worst

Table 1. Enforcement level (\%) of smoke-free regulations by facilities in 2018-2019 in Georgia

$\begin{array}{ccccccccc} & \text { Educational } & \text { Medical } & \text { Public } & \text { Cinema } & \text { Restaurants } & \text { Hotels } & \begin{array}{c}\text { Beauty } \\ \text { Palons } \\ \text { transport }\end{array} \\ \text { May-Dec } 2018 & 94 & 95 & 95.4 & 86.3 & 97.6 & 96.9 & 99 & 97.6 \\ \text { May-Dec } 2019 & 98.7 & 97.4 & 98.4 & 97.9 & 97.4 & 99.5 & 99.9\end{array}$

*FCTC Implementation and Monitoring Center in Georgia. Data collected during of implementation of health promotion state program during 2017-2019. FCTC Implementation and Monitoring Center in Georgia; 2020. 
situation was observed in the hospitality sector in 2017, as the level of air pollution ( $\mathrm{PM}<2.5 \mu \mathrm{m}$, which mostly relates to cigarette smoke $)^{19}$ on average was $1408 \mu \mathrm{g} / \mathrm{m}^{3}$, which is 56 times higher than the WHO standard of PM $25 \mu \mathrm{g} / \mathrm{m}^{3}$. After introduction of the law, by the end of 2018, the average air pollution level in the same sector was only $126 \mathrm{\mu g} /$ $\mathrm{m}^{3}$ and became $117 \mu \mathrm{g} / \mathrm{m}^{3}$ in 2019. The data shows that exposure concentrations have fallen by about 91\% after the smoking prohibition was introduced.

The air pollution in public entities, where it was $531 \mathrm{\mu g} / \mathrm{m}^{3}$ on average, was exceeding the norm 21 times in 2017, and it decreased to $112 \mu \mathrm{g} / \mathrm{m}^{3}$ at the end of 2018 and became $98 \mu \mathrm{g} / \mathrm{m}^{3}$ at the end of 2019. The exposure concentrations have fallen by about $80 \%$ in public entities. Regarding medical facilities, air pollution was $219 \mu \mathrm{g} / \mathrm{m}^{3}$, but by the end of 2018 it had dropped to $97 \mu \mathrm{g} / \mathrm{m}^{3}$ and remained at $98 \mathrm{\mu g} / \mathrm{m}^{3}$ in 2019. Survey data from STEPS 2016 and Tobacco National Survey (TNS) 2019 show that SHS exposure declined by $4.4 \%$ in homes and by $4.7 \%$ at work places in Georgia ${ }^{10,20}$.

\section{Quitline operation}

Quitline services were substantially activated after entry into force of the new tobacco control legislation in both directions - quit smoking as well as provision of consultations concerning implementation of the law. The Quitline statistics in the NCDC only exist since 1 Jan 2018.

According to the data from the NCDC (unpublished data, 2019)**, the number of users of the Quitline service increased significantly after 1 May 2018 when the new regulations entered into force. During the period of 1 May to 20 December 2018 , the number of received calls was 3027 (2673 men, 354 women). In all, 2109 persons received consultations regarding smoking cessation, 288 obtained information regarding new regulations, and 630 were referred to different healthcare facilities. To compare with the data from January to April 2018, in that period only 193 consultations for smoking cessation were conducted.

Statistics during of 2019 showed that the number of calls increased to 4288 (3734 men and 554 women), when 2730 persons received consultations regarding smoking cessation, 1037 obtained information regarding new regulations, and 954 persons were
Table 2. Registered new cases of acute myocardial infarction (AMI) during 2016-2019

$\begin{array}{lllll} & 2016 & 2017 & 2018 & 2019 \\ \text { AMI new cases } & 4588 & 4678 & 3211 & 3162\end{array}$

Source: Ministry of Health of Georgia 2020.

referred to different healthcare facilities.

\section{Impact of smoke-free legislation on population health}

According to the present assessment, smoke-free regulations enacted since May 2018 had a high level of compliance. Equalized taxes on filtered cigarettes since January 2019, and non-filtered cigarettes since Nov 2019, have increased taxes on roll-your-own tobacco $^{21}$. Such measures together affected smoking prevalence which decreased by $3 \%$ among the general population and by $9 \%$ among smokers, during $2016-$ 2019. Consumption of tobacco products decreased by $15 \%$ during the same period ${ }^{20}$.

\section{Acute myocardial infarction (AMI)}

According to the data of the Ministry of Health in 2018 new cases of AMI decreased by $31 \%$ compared with 2017, and by $32 \%$ in 2019 compared with 2017 (3162 vs 4678) (Table 2). According to the experts' opinion, such a decrease can be related to improvements in the field of cardiovascular surgery, as well as a dramatic decrease in exposure to SHS after May 2018.

\section{DISCUSSION}

Findings from this study are linked to relevant studies conducted globally during the last decades. More than $95 \%$ of compliance of comprehensive smokefree legislation created smoke-free environments in indoor public places in Georgia. The indoor air quality improved by $91 \%$ in the hospitality sector, by $80 \%$ in public settings, and sufficiently in healthcare facilities. Evidences from different countries show that air quality has been improved, after smoke-free laws came into force ${ }^{22-25}$.

The literature also indicates that wide-ranging bans reduce exposure to SHS and effects on health due to the restrictions on smoking prohibition in public places; which are followed by as much as a $10-20 \%$ reduction in hospital admissions for 
acute coronary events in the general population in the first year post-ban. The precise magnitude of the reduction in admissions is uncertain, but it will vary with the background incidence of heart disease, on the prevalence of exposure to SHS resulting from the ban, and the extent of the legislation and its implementation. Georgia has a high rate of compliance to smoke-free legislation and a decline in acute respiratory and cardiovascular diseases ${ }^{7,8}$.

Most of the studies on the impact of smoke-free legislation on population health have examined the short-term effects of legislation on admissions for acute myocardial infarction (AMI) and related cardiac condition and acute pulmonary diseases. The majority of the studies analyzed data 12 or 18 months before smoking prohibition in public places and 12 or 18 months after the prohibition. The studies with the largest reductions in hospital admissions (about $30 \%$ ) were conducted on relatively small populations and included only a small number of admission events. Larger population studies, which covered large geographical areas and included thousands of cases, but did not include control areas, found smaller reductions, between $8 \%$ and $17 \%{ }^{9,26,27}$.

In Georgia we used the same time period for the first stage and observed appropriate health and other related statistics during one and half years after a new tobacco control regulation has entered into force. In our study, we covered all Georgian population data and were able to conclude that new cases of AMI declined by $32 \%$ during 2017 2019.

It is evident that after entering into force, the smoke-free legislation increases demand on Quitline services ${ }^{28-30}$. The results we obtained from the study also show around $30 \%$ increase in calls received after new regulations and an increase in smoking cessation consultations by $23 \%$.

\section{Strengths and limitations}

One year and half to observe the positive changes on population health is a small time frame, but it gave us a positive trend in the impact of a comprehensive smoking ban in public places and transport. There is need to continue data collection and analyses during a long-term period to learn more about the impact of such measures to the health condition of the Georgian population. The new cases of AMI, a disease related with SHS, were assessed and found to have declined after implementation of the comprehensive smoke-free legislation, however, further observation for a longer time and in-depth analysis are necessary to make conclusions regarding such an association.

\section{CONCLUSIONS}

Comprehensive smoke-free policy with high level of compliance $(\geq 95 \%)$ had a positive impact on the decline of SHS exposure and tremendous improvement of indoor air quality in public places and promotes decreases in illnesses related to acute cardio-vascular system (AMI) in Georgia. Also, demand has increased on smoking-cessation services.

\section{REFERENCES}

1. World Health Organization. Tobacco Key facts. Updated July 26, 2021. Accessed October 25, 2021. https://www. who.int/news-room/fact-sheets/detail/tobacco

2. Centers for Disease Control and Prevention. Health Effects of Cigarette Smoking. Updated December 10, 2020. Accessed October 25, 2021. https://www.cdc. gov/tobacco/data_statistics/fact_sheets/health_effects/ effects_cig_smoking/index.htm

3. Royal College of Physicians. Nicotine Addiction in Britain: A Report of the Tobacco Advisory Group of the Royal College of Physicians. Royal College of Physicians; 2000.

4. World Health Organization. Second-hand smoke and children. October 2011. Accessed October 25, 2021. https://www.who.int/ceh/capacity/tobaccol.pdf

5. American Cancer Society. Secondhand Smoke: Just the facts. July 2014. Accessed October 25, 2021. https:// www.fightcancer.org/sites/default/files/Facts-AboutSecondhand-Smoke.pdf

6. International Agency for Research on Cancer, World Health Organization. Evaluating the Effectiveness of Smoke-free Policies. IARC; 2009. IARC Handbooks of Cancer Prevention. Accessed October 25, 2021. https:// www.iarc.who.int/wp-content/uploads/2018/07/ handbook13.pdf

7. Hahn E. Smokefree Legislation, a Review of Health and Economic Outcomes Research. Am J Prev Med. 2010;39(6S1):S66-S76. doi:10.1016/j.amepre.2010.08.013

8. Goodman PG, Haw S, Kabir Z, Clancy L. Are there health benefits associated with comprehensive smokefree laws. Int J Public Health. 2009;54(6):367-378. doi:10.1007/s00038-009-0089-8

9. Frazer K, Callian J, McHugh J, et al. Legislative smoking 
bans for reducing harms from secondhand smoke exposure, smoking prevalence and tobacco consumption. Cochrane Database Syst Rev. 2016;2(2):CD005992. doi:10.1002/14651858.CD005992.pub3

10. World Health Organization. STEPS 2016: Georgia. National Center for Disease Control and Public Health. November 12, 2018. Accessed October 25, 2021. https:// extranet.who.int/ncdsmicrodata/index.php/catalog/223

11. World Health Organization. Global Youth Tobacco Survey Fact Sheet: Georgia 2017. Updated April 2, 2018. Accessed October 25, 2021. https://ncdc.ge/\#/pages/ file/fc5c147c-98b0-41ea-9420-e30727f7d134

12. National Center for Disease Control and Public Health. Georgia 2016: European School Survey Project on Alcohol and Other Drugs. 2016. Accessed October 25, 2016. https://ncdc.ge/\#/pages/file/f501edd0-ab9449b3-bcd3-b66c9db91ce5

13. United Nations. Investment Case for Tobacco Control in Georgia. National Center for Disease Control and Public Health of Georgia, United Nations Development Programme, RTI International, WHO FCTC Secretariat, World Health Organization; 2019. Accessed October 25, 2021. https://www.undp.org/publications/investmentcase-tobacco-control-georgia

14. Institute of Health Metrics and Evaluation. The Global Burden of Disease Profile: Georgia. 2017. Accessed October 25, 2021. http://www.healthdata.org/sites/ default/files/files/country_profiles/GBD/ihme_gbd_ country_report_georgia.pdf

15. Goodchild M, Nargis N, d'Espaignet E. Global economic cost of smoking-attributable diseases. Tob Control. 2018;27(1):5864. doi:10.1136/tobaccocontrol-2016-053305

16. Ekpu V, Brown A. The Economic Impact of Smoking and of Reducing Smoking Prevalence: Review of Evidence. Tob Use Insights. 2015;8:1-35. doi:10.4137/TUI.S15628

17. Parliament of Georgia. Law on Tobacco Control [in Georgian]. 2017. Accessed October 25, 2021. https:// matsne.gov.ge/document/view/1160150?publication $=3$

18. Bakhturidze G. Evaluating health and economic impact of tobacco control law in Georgia. World Health Organization, FCTC Implementation and Monitoring Center in Georgia; 2019. Accessed October 25, 2021. https://www. researchgate.net/publication/341278009_Evaluating_ health_and_economic_impact_of_tobacco_control_law_ in_Georgia_Report_on_Georgian\#fullTextFileContent

19. World Health Organization. WHO Air quality guidelines for particulate matter, ozone, nitrogen dioxide and sulfur dioxide: Global update 2005. World Health Organization; 2006. Accessed October 25, 2021. https://apps.who.int/ iris/bitstream/handle/10665/69477/WHO_SDE_PHE_ OEH_06.02_eng.pdf?sequence $=1$

20. National Center for Disease Control and Public Health. National Youth Tobacco Survey (NYTS): Georgia 2019. Accessed October 25, 2020. https://www.ncdc.ge/\#/ pages/file/22c5e2c0-36d9-4a08-975c-03fa09d21c2e
21. Government of Georgia. Law of Georgia: Tax Code. number 3591. Updated August 2, 2021. Accessed October 25, 2021. https://matsne.gov.ge/ka/document/ view/1043717?publication $=175$

22. Connolly G, Carpenter C, Travers M, et al. How smoke-free laws improve air quality: A global study of Irish pubs. Nicotine Tob Res. 2009;11(6):600-605. doi:10.1093/ntr/ntp038

23. Semple S, Tongeren M, Galea K, et al. US Smoke-Free Legislation: Changes in PM2.5 Concentrations in Bars in Scotland, England, and Wales. TAnn Occup Hyg. 2010;54(3):272-280. doi:10.1093/annhyg/mep094

24. Shamo F, Wilson T, Kiley J et al. Assessing the effect of Michigan's smoke-free law on air quality inside restaurants and casinos: a before-and-after observational study. MBJ Open. 2015;5(7):e007530. doi:10.1136/bmjopen-2014-007530

25. Sadykova J, Baizhaxynova A, Crape B. Air quality at venues of mixed smoking policies in Kazakhstan. Tob Induc Dis. 2020;18(September):79. doi:10.18332/tid/127230

26. Tan C, Glantz S. Association Between Smoke-Free Legislation and Hospitalizations for Cardiac, Cerebrovascular, and Respiratory Diseases. Circulation. 2012;126(18):21772183. doi:10.1161/CIRCULATIONAHA.112.121301

27. Rando-Matos Y, Pons-Vigues M, Lopez M, et al. Smokefree legislation effects on respiratory and sensory disorders: A systematic review and meta-analysis. PLoS One. 2017;12(7):e0181035. doi:10.1371/journal.pone.0181035

28. Park J, Mihn L, Shin S, et al. Influence of new tobacco control policies and campaigns on Quitline call volume in Korea. Tob Induc Dis. 2019;17(March):21. doi:10.18332/tid/104674

29. North America Quitline Consortium. Smokefree Policy Changes: Promoting Quitlines to Maximize the Cessation Benefit. 2009. Accessed October 25, 2021. https://cdn. ymaws.com/www.naquitline.org/resource/resmgr/docs/ naqc_factsheet_smokefreepoli.pdf

30. Chan S, Wong D, Fong D. Short-term impact of new smoke-free legislation on the utilization of a quitline in Hong Kong. Nicotine Tob Res. 2009;11(4):356-361. doi:10.1093/ntr/ntp025 
CONFLICTS OF INTEREST

The authors have each completed and submitted an ICMJE Form for Disclosure of Potential Conflicts of Interest. The authors declare that they have no competing interests, financial or otherwise, related to the current work. G. Bakhturidze reports grands from WHO FCTC2030 project, outside the submitted work.

\section{FUNDING}

There was no source of funding for this research.

ETHICAL APPROVAL AND INFORMED CONSENT

Ethical approval and informed consent were not required for this study.

\section{DATA AVAILABILITY}

The data supporting this research are available from the authors on reasonable request.

PROVENANCE AND PEER REVIEW

Not commissioned; externally peer reviewed. 